\title{
Communication
}

\section{Time to Substitute Wood Bioenergy for Nuclear Power in Japan}

\section{Nophea Sasaki ${ }^{1,2, *}$, Toshiaki Owari ${ }^{3}$ and Francis E. Putz ${ }^{4}$}

1 Graduate School of Applied Informatics, University of Hyogo, 7-1-28-6F Minatojima-minamimachi, Chuo-ku, Kobe 650-0047, Japan

2 Harvard Forest, Harvard University, 324 North Main Street, Petersham, MA 01366, USA

3 Graduate School of Agricultural and Life Sciences, University of Tokyo, 61 Higashi-machi, Yamabe, Furano, Hokkaido 079-1563, Japan; E-Mail: owari@uf.a.u-tokyo.ac.jp

4 Department of Biology, University of Florida, Gainesville, FL 32611-8526, USA; E-Mail: fep@ufl.edu

* Author to whom correspondence should be addressed; E-Mail: nop.kankyo@ai.u-hyogo.ac.jp; Tel./Fax: +81-78-303-1929.

Received: 29 April 2011; in revised form: 17 June 2011 / Accepted: 4 July 2011 / Published: 6 July 2011

\begin{abstract}
Damage to the Fukushima Nuclear Power Plant by the recent earthquake and tsunami that hit northern Japan should stimulate consideration of alternative sources of energy. In particular, if managed appropriately, the 25.1 million ha of Japanese forests could be an important source of wood biomass for bioenergy production. Here, we discuss policy incentives for substituting wood bioenergy for nuclear power, thereby creating a safer society while better managing the forest resources in Japan.
\end{abstract}

Keywords: carbon emissions; forest management; forest thinning; nuclear crisis; woody biomass

\section{Nuclear Power Disasters and Power Generation}

Earthquake-related damage to the nuclear power plants of the Tokyo Electric Power Company (TEPCO) in Fukushima represents the largest economic disaster to hit Japan since World War II. The Yomiuri Shimbun newspaper estimated on 1 April 2011 that damages due to the 11 March earthquake and related events at 400 billion yen (US\$4.7 billion) for decommissioning the four reactors plus about 
$\$ 133$ billion in liabilities for compensation if the current nuclear crisis lasts for 2 years (according to Bloomberg's 31 March 2011 issue). TEPCO's stock prices are falling sharply as fires in the reactors and radiation leaks continue; during just the first two weeks after the quake, TEPCO's shares lost about 3 trillion yen. The effects of this unfolding disaster on human health, agricultural soils, and water resources are likely to persist for as long as 100 years [1-4]. Short-term losses of power are being compensated for by increased production by coal and oil-fired power plants, but nuclear power is not the only source of low-emission energy.

Japan annually consumes about 858.5 billion $\mathrm{kWh}$ of electricity produced by oil (46\%), coal (21\%), natural gas (17\%), nuclear fuel (11\%), and hydroelectric (3\%) power plants [5]. Despite the large potential for producing electricity using woody biomass [6] and solar power, only less than 5\% of Japan's electricity is currently from renewable sources. For the Tokyo metropolitan area, Yamanashi Prefecture, and the eastern portion of Shizuoka Prefecture prior to the quake, the large electric utility TEPCO supplied 253.2 billion kWh mostly from geothermal sources and nuclear power (Table 1).

The 80.9 billion kWh of electricity once generated by TEPCO's nuclear facility could be provided by the burning of 14.6 million tonnes of woody biomass. Based on harvest data from 2003, total annual wood biomass production in Japan is more than twice that amount, about 31.7 million tonnes [7]. Between 2007 and 2012, the Japanese government implemented special thinning activities in young plantations (mainly 20-45 years old) to increase annual rates of carbon sequestration to the 13 million tonnes as cap set by the 2001 Marrakesh Accord of the Kyoto Protocol to the United Nations Convention on Climate Change (UNFCCC). Etoh et al. [6] estimated the thinning residues in forests (tops, branches, and foliage) and waste at wood processing factories at 68.6 million tonnes of woody biomass available annually for generating 381.0 billion $\mathrm{kWh}$ (see [6] for calculation) or about 4.7 times that produced by TEPCO's nuclear power or 1.5 times higher than that generated from all sources by TEPCO. Therefore, the recent earthquake-driven nuclear disasters would have been avoided if woody biomass instead of nuclear power was used for electricity generation.

Table 1. Power generation by TEPCO and matching biomass requirements (data from 2009).

\begin{tabular}{|c|c|c|}
\hline Types & $\begin{array}{l}\text { Electricity } \\
\text { (billion kWh) }\end{array}$ & $\begin{array}{l}\text { Wood Biomass Equivalent }{ }^{(1)} \\
\text { (million tonnes) }\end{array}$ \\
\hline Geo-thermal & 161.20 & 29.0 \\
\hline Nuclear & 80.90 & 14.6 \\
\hline Hydroelectric & 10.10 & 1.8 \\
\hline Natural gas energy & 0.01 & 0.0 \\
\hline Purchased from other companies & 54.00 & 9.7 \\
\hline Total & 306.21 & 55.1 \\
\hline $\begin{array}{l}\text { If disposed wood residues left in forests and wood } \\
\text { wastes in wood processing factories were used. }\end{array}$ & 381.04 & $68.6^{(2)}$ \\
\hline
\end{tabular}




\section{Forestry Development in Japan}

Japan is heavily forested country, with a total forest cover of 25.1 million ha or $67 \%$ of the total land area. Covering 10.4 million ha [9], Japanese plantation forests are dominated by Sugi (Japanese cedar, Cryptomeria japonica) and Hinoki (Japanese cypress, Chamaecyparis obtusa) altogether accounting for $70.6 \%$ of all planted species. Intensive tree planting was carried out after World War II to meet the high demand for domestic timber. The industry also created forest sector jobs while it improved forest ecosystem functions. Unfortunately, a policy introduced in 1961 to promote foreign timber imports caused domestic timber to no longer be competitive [10]. As a result of this loss of market share, forest management nearly ceased throughout the nation, Japan's wood self-sufficiency decreased from $86.7 \%$ in 1966 to $19.2 \%$ in 1999 , and employment in the forest sector declined by $80 \%$. Furthermore, younger-generation Japanese have not been interested in working in the forestry sector because of low salaries, resulting in an aging work force [11].

Although many Japanese plantation forests have reached the age at which they require thinning to promote forest growth and health (e.g., resistance to diseases and soil erosion), thinning operations are rare due to their high operating costs [12] and low prices for the harvested material [11]. In the overly crowded stands (unmanaged stands), little sunlight reaches the ground (Figure 1), which inhibits the growth of understory plants, renders sloped areas susceptible to erosion, and deprives wildlife of food. One indirect consequence of this wildlife food shortage is increased incidents of attacks on humans by bears and wild boars as the animals search for food in agricultural and suburban areas [13].

Figure 1. Managed and unmanaged stands in private forests in Hyogo prefecture, Japan. While undergrowth vegetation can be seen in managed stands (right), no undergrowth vegetation was able to establish in the unmanaged stand (left). Note: the fallen trees in the unmanaged stand were the result of late pre-commercial thinning to reduce the highly dense stem density.

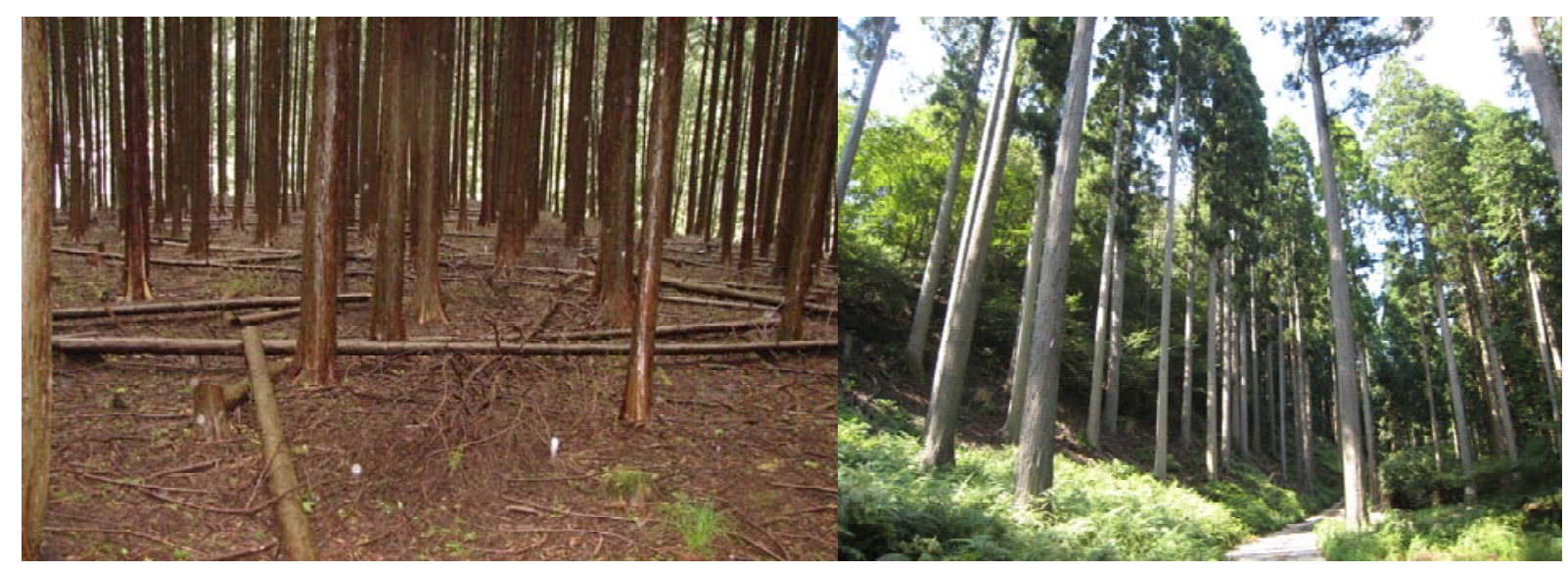

Another result of not managing the domestic forests of Japan is that forests elsewhere are destroyed to provide the important forest products, a prime example of the so-called "illusion of preservation" [14]. In particular, Japanese demands for cheap foreign wood contribute substantially to the destruction of tropical forests from which 1.1-2.2 billion tonnes of carbon (about 4.0-8.1 billion tonnes $\mathrm{CO}_{2}$ ) [15-17] are emitted annually. Furthermore, new initiatives to promote improved forest management in the 
tropics, including the UNFCCC program to reduce emissions from deforestation and forest degradation and enhance carbon sinks (REDD+) are likely to result in reduced wood supplies and higher prices as timber will increasingly be sourced from responsibly managed forests.

\section{Promoting Wood Bioenergy as Incentives for Forest Management}

Greenhouse gas emissions from nuclear power plants are small and could greatly help Japan meet its emission reduction targets under the Kyoto Protocol, which Japan committed to cut by $6 \%$ between 2008 and 2012 (first commitment period), and pledged to reduce $25 \%$ by 2020 , and $50 \%$ by 2050 compared to emissions in 1990. Nevertheless, given the latest nuclear disaster and the likelihood of future disasters due to the vulnerability of Japan to earthquakes, using nuclear energy to generate electricity and reduce greenhouse gas emissions is no longer a feasible option. Not only do such disasters hurt the economy and society, they also stimulate increased use of fossil fuel to maintain the power supply, which means more greenhouse gas emissions. In fact, given this problem, Japan is reconsidering its emissions reduction pledges for the post-Kyoto climate agreements whose discussions will be held at the 17th session of the UNFCCC Conference of the Parties in December 2011 in Duran, South Africa. Clearly alternative but culturally, socially, economically, and environmentally alternative sources of energy must be provided. The option to use forest biomass for generating power instead of nuclear or $\mathrm{CO}_{2}$-emitting fossil fuels deserves serious consideration. In addition to the emissions and safety benefits, by so doing, Japan could revive its forest industries and forest ecosystems while creating jobs for young people who are urgently needed to replace the aging workers. Culturally, trees and forests are important for Japanese society as indicated by the fact that 10,000 commonly used Chinese characters (Kanji) in the Japanese language are the combination of tree, forest, or both characters. By thinning, forests can also increase timber productivity [18] and promote the establishment of the understory vegetation [19] and decrease forest vulnerability to insects and fungi [20]. Furthermore, local people in Japan traditionally manage red pine (Pinus densiflora) for an economically valuable mushroom matsutake or pine mushrooms through the thinning of over-story vegetation.

Although thinning was once considered too costly [21,12], with a viable market for woody biomass as well as for timber products [22], it could be economically viable. In particular, the $70 \%$ of the thinned wood that is currently left on site [6] could be utilized for bioenergy production. Given that most of Japan's plantations are on steep terrain, highly productive harvesting machines, like those used in Europe, need to be developed. Better harvesting equipment would enhance operational efficiency and increase worker safety and comfort, which would attract young workers to the forestry business. Since $55 \%$ of Japan's forests are privately owned by more than 900,000 owners [23], small areas of forests to be thinned could be aggregated into a larger operational unit for the efficient use of harvesting equipment. Thinning activities could also be promoted through payments for ecosystem services to forest owners, thereby increasing revenues from managing the forests.

Globally, wood biomass for bioenergy production has been increasingly recognized for its multiple benefits including but not limit to increasing forest productivity, generating jobs, and reducing carbon emissions by substituting fossil fuels for energy generation [24-27]. Nevertheless, wood biomass for energy or wood bioenergy in Japan was once considered too costly [28,29], but in the wake of nuclear 
disasters and in recognition of Japan's emission reduction commitment, this may no longer be the case. One impediment to bioenergy in Japan is the lack of bioenergy policies such as those in the European Union [30]. In trying to reach its goal of a $20 \%$ share of energy from renewable sources by 2020 , the EU enacted various policies such as fixed prices for renewable energy and tax exemptions on bioenergy while it imposed taxes on fossil-fuel based energy and liberalized the electricity market. The EU also provides grants and loans for setting up bioenergy production and mandates the use of bioenergy. Even with the currently high production costs in Japan, the price of bioenergy is currently only about 5 yen $\mathrm{kWh}^{-1}$ [6] compared to 21 yen and 25 yen $\mathrm{kWh}^{-1}$ for energy generated by the combustion of fossil fuels or with solar panels, respectively. Even with such a low price, large power companies are reluctant to enter into contracts for the purchase of bioenergy [30]. With appropriate tax policies, the costs of bioenergy production will become even lower compared to that from fossil fuel production. For example, the production cost for bioenergy in Sweden is currently $120 \%$ lower than that of fossil fuels when energy, carbon, and sulfur taxes are imposed, in the absence of which bioenergy production costs would be $38 \%$ higher [30]. Also, liberalization of the electricity market would help break the monopolies of large electricity suppliers, thereby creating more opportunities for local wood bioenergy suppliers. Furthermore, setting up national and regional authorities to oversee the good management practices of power companies could help enforce the bioenergy policies while policy incentives are introduced.

\section{Conclusions}

Taking into full account the recent and potential future nuclear disasters, the risks of unmanaged forests, lack of forestry workers, and emission reduction obligations, Japan needs to rethink its energy policies to reduce reliance on nuclear and fossil fuel generated energy. Further research on wood bioenergy production and forest resource availability is needed to inform development of effective policies and enforcement mechanisms.

\section{Acknowledgements}

We thank C. Hart, K. Tanaka, D. Fernandes, and S. Chay for their suggestions and insightful comments on earlier versions of this paper. This study is partially supported by a Grant-in-Aid for Scientific Research (No. 18402003) from the Ministry of Education, Culture, Sports, Science and Technology of Japan.

\section{References}

1. Havenaar, J.M.; Rumyantzeva, G.M.; van den Brink, W.; Poelijoe, N.W.; van den Bout, J.; van Engeland, H.; Koeter, M.W. Long-term mental health effects of the Chernobyl disaster: An epidemiologic survey in two former Soviet regions. Am. J. Psychiatry 1997a, 154, 1605-1607.

2. Havenaar, J.; Rumyantzeva, G.; Kasyanenko, A.; Kaasjager, K.; Westermann, A.; van den Brink, W.; van den Bout, J.; Savelkoul, J. Health effects of the Chernobyl disaster: Illness or illness behavior? A comparative general health survey in two former Soviet regions. Environ. Health Perspect. 1997b, 105, 1533-1537. 
3. Kovalchuk, I.; Kovalchuk, O.; Arkhipov, A.; Hohn, B. Transgenic plants are sensitive bioindicators of nuclear pollution caused by the Chernobyl accident. Nat. Biotechnol. 1998, 16, 1054-1059.

4. Ramana, M.V. Nuclear power: Economic, safety, health, and. environmental issues of near-term technologies. Annu. Rev. Environ. Resour. 2009, 34, 127-152.

5. Energy Information Administration 2011 Country analysis briefs: Japan. Available online: http://www.eia.doe.gov/cabs/Japan/pdf.pdf (accessed on 18 April 2011).

6. Etoh, H.; Sasaki, N.; Chay, S.; Ninomiya, H. Carbon emission reduction potentials through thinned wood in Japan. iForest 2011,4, 107-112.

7. Yoshioka, T.; Hirata, S.; Matsumura, Y.; Sakanishi, K. Woody biomass resources and conversion in Japan: The current situation and projections to 2010 and 2050. Biomass Bioenergy 2005, 29, 336-346.

8. Hall, D.O. Biomass energy in industrialised countries. A view of the future. For. Ecol. Manag. 1997, 91, 17-45.

9. Forestry Agency. Forests and Forestry Statistics in 2008; Forestry Agency: Tokyo, Japan, 2008.

10. Iwai, Y. Forestry and the Forest Industry in Japan; UBC Press: Vancouver, Canada, 2002.

11. Food and Agriculture Organization (FAO). Japan Forestry Outlook Study; Asia-Pacific Forestry Sector Outlook Study II; Working Paper Series; Working Paper No. APFSOS II/WP/2010/30; FAO: Bangkok, Thailand, 2010.

12. Yoshioka, T.; Aruga, K.; Nitami, T.; Sakai, H.; Kobayashi, H. A case study on the costs and the fuel consumption of harvesting, transporting, and chipping chains for logging residues in Japan. Biomass Bioenergy 2006a, 30, 342-348.

13. Saitoh, T.; Ishibashi, Y.; Kanamori, H.; Kitahara, E. Genetic status of fragmented populations of the Asian black bear Ursus thibetanus in western Japan. Popul. Ecol. 2001, 43, 221-227.

14. Berlik, M.M.; Kittredge, D.R.; Foster, D.R. The illusion of preservation: A global environmental argument for the local production of natural resources. J. Biogeogr. 2002, 29, 1557-1568.

15. Achard, F.; Eva, H.D.; Mayaux, P.; Stibig, H.J.; Belward, A. Improved estimates of net carbon emissions from land cover change in the tropics for the 1990s. Global Biogeochem. Cycles 2004, 18, doi:10.1029/2003GB002142.

16. Gullison, F.R.; Frumhoff, C.P.; Canadell, G.J.; Field, B.C.; Nepstad, C.D.; Hayhoe, K.; Avissar, R.; Curran, M.L.; Friedlingstein, P.; Jones, D.C.; et al. Tropical forests and climate policy. Science 2007, 316, 985-986.

17. Houghton, R.A. Revised estimates of the annual net flux of carbon to the atmosphere from changes in land use and land management 1850-2000. Tellus 2003, 55B, 378-390.

18. Mead, D.J. Opportunities for improving plantation productivity. How much? How quickly? How realistic? Biomass Bioenergy 2005, 28, 249-266.

19. Fukata, H.; Watanabe, N.; Kajihara, N.; Tsukamoto, J. Dynamics of undergrowth and its application to vegetation control of planted Chamaecyparis obtusa Endl. Forests with special reference to mitigation of surface soil loss. J. Jpn. For. Soc. 2006, 88, 231-239 (in Japanese).

20. Sato, S. Relationships between insect and disease pest damages and thinning practice in plantations of Japanese red cedar and Hinoki cypress in Japan. Bull. FFPRI 2007, 6, 135-143 (in Japanese). 
21. Yoshimoto, A.; Marušák, R. Evaluation of carbon sequestration and thinning regimes within the optimization framework for forest stand management. Eurasian J. For. Res. 2007, 126, 315-329.

22. Sedjo, R.A. The potential of high-yield plantation forestry for meeting timber needs. New For. 1999, 17, 339-360.

23. Ministry of Agriculture, Forestry and Fisheries. Summary Report: Census of Agriculture and Forestry 2010; Ministry of Agriculture, Forestry and Fisheries: Tokyo, Japan, 2011.

24. Marland, G.; Schlamadinger, B. Forests for carbon sequestration or fossil fuel substitution? A sensitivity analysis. Biomass Bioenergy 1997, 13, 389-397.

25. Baral, A.; Guha, G.S. Trees for carbon sequestration or fossil fuel substitution: The issue of cost vs. carbon benefit. Biomass Bioenergy 2004, 27, 41-55.

26. Faaij, A.P.C. Bio-energy in Europe: Changing technology choices. Energy Policy 2006, 34, 322-342.

27. Nabuurs, G.J.; Schelhaas, M.J. Spatial distribution of whole-tree carbon stocks and fluxes across the forests of Europe: Where are the options for bio-energy. Biomass Bioenergy 2003, 24, 311-320.

28. Ooki, Y. Problem Investigation for Woody Biomass Generation Introduction in Japan; The Institute of Energy Economics: Tokyo, Japan, 2003; pp. 1-10 (in Japanese).

29. Endo, M. The Energy Use of Woody Biomass-Trend and Problems; Investigation and Information, National Diet Library: Tokyo, Japan, 2006; Volume 510, pp. 1-10 (in Japanese).

30. Etoh, H.; Sasaki, N. Comparison on promotion policies for utilization of woody biomass between European countries and Japan. J. Jpn. For. Soc. 2006, 92, 88-92.

(C) 2011 by the authors; licensee MDPI, Basel, Switzerland. This article is an open access article distributed under the terms and conditions of the Creative Commons Attribution license (http://creativecommons.org/licenses/by/3.0/). 